\title{
Erratum: Translation of field tracer-test results into bounding predictions of matrix diffusion in the shallow subsurface at Idaho National Laboratory, USA
}

\section{Paul W. Reimus • Catherine L. Duke •} Robert C. Roback

Erratum to: Hydrogeology Journal (2011) 19:1021-1037 DOI 10.1007/s10040-010-0685-y

The definition of $R_{m}$ on p.1035 (section Considerations for sorbing solute transport) is incorrect. Specifically, the $\alpha$ in the expression should be replaced with $\phi$ (matrix porosity). $\alpha$ is defined a few lines earlier, and it includes $R_{m}$, so the use of $\alpha$ in the definition of $R_{m}$ is confusing (recursive) and incorrect. The correct definition of $R_{m}$ is:

$R_{m}=$ retardation factor in matrix or stagnant porosity

$$
=1+\frac{\rho_{B}}{\phi} K_{d}
$$

Also, Fig. 4 incorrectly refers to $\phi_{m}$ as the matrix porosity. This is inconsistent with the rest of the manuscript, where matrix porosity is referred to as $\phi$. The correct figure is presented here.

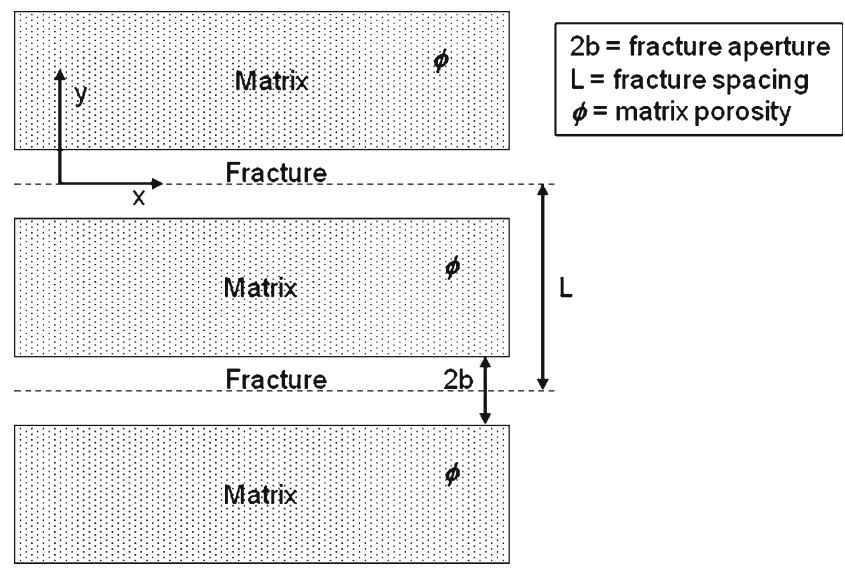

Fig. 4 Fracture and matrix geometry assumed in the RELAP model

Published online: 5 January 2012

(C) Springer-Verlag 2011

The online version of the original article can be found at http://dx. doi.org/10.1007/s10040-010-0685-y.

P. W. Reimus $(\varpi) \cdot$ R. C. Roback

Los Alamos National Laboratory,

PO Box 1663, Los Alamos, NM 87544, USA

e-mail: preimus@lanl.gov

Tel.: +1-505-6652537

Fax: +1-505-6062258

C. L. Duke

1550 East Prince Rd, Tucson, AZ 85719, USA 